\title{
Breast meat quality of chickens with divergent growth rates and its relation to growth curve parameters
}

\author{
Philipp C. Muth and Anne Valle Zárate \\ Animal Husbandry and Breeding in the Tropics and Subtropics, Hans-Ruthenberg-Institute of \\ Agricultural Sciences in the Tropics, University of Hohenheim, 70593 Stuttgart, Germany \\ Correspondence to: Philipp C. Muth (p_muth@uni-hohenheim.de)
}

Received: 10 June 2017 - Revised: 18 October 2017 - Accepted: 19 October 2017 - Published: 28 November 2017

\begin{abstract}
The effects of the increase of body weight of contemporary broilers during growth on functional meat quality and color characteristics of the chicken breast muscle are controversially debated. Therefore, male chickens $(n=264)$ of a fast-growing commercial broiler (Ross 308$)$ and two slow-growing experimental meattype chicken lines were compared at equal age and at similar body weight in order to investigate the effect of growth rate on selected functional breast meat traits and meat color. Additionally, the breast meat characteristics of birds with different growth profiles were compared within lines. When the body weight of commercial broilers reached about 40 to $60 \%$ of their growth potential, they exhibited particularly high ultimate $\mathrm{pH}$ values compared with slow-growing lines. The ability of the meat of fast-growing broilers to retain water during cooking was impaired (5 to 16 percentage points increased cooking loss compared to slow-growing lines), which, in contrast to $\mathrm{pH}$, was only marginally affected by body weight and/or age at slaughter. No unfavorable correlations of breast meat quality traits with the growth profile, represented by growth curve parameters derived from the GompertzLaird equation, were detected within any of the investigated chicken lines. It is noteworthy that the associations of ultimate $\mathrm{pH}$ and cooking loss with maximum growth speed indicate a non-linear relationship. Thus, some of the functional characteristics of breast meat of the fast-growing broiler resembled the white-striping defect described for poultry meat, but the hypothesis that selection on increased growth rates is detrimental for meat quality per se could not be confirmed. In fact, an elevated growth potential in particular, i.e., body weight at maturity, could have some beneficial effects for the water-holding capacity of breast meat, regardless of the genotypic growth rate.
\end{abstract}

\section{Introduction}

From the mid-20th century onwards, poultry breeders applied within-line selection schemes to improve production traits of meat-type chickens (later termed "broilers") and maximize the profitability of chicken meat production (Hunton, 2006). Hybridization allowed the achievement of further genetic improvement by additionally exploiting nonadditive genetic effects, and, consequently, nowadays, broilers are the outcome of pyramidal-structured crossbreeding programmes, whereas in the top tier a few dozen purebred great-grandparental lines are selected for a broad range of traits (Neeteson-van Nieuwenhoven et al., 2013). Since the early days of poultry breeding, remarkable successes in economically important traits - such as growth rate, breast meat yield and feed efficiency - have been realized, as impressively demonstrated by Havenstein et al. (2003) and Schmidt et al. (2009), who compared growth performance and carcass composition of modern broilers to lines that remained unselected since the 1950s.

In broiler production, the growth rate, given as body weight at a specific age, is of higher practical relevance than the mere growth potential, given as body weight at maturity because slaughter generally takes place before the animals reach their mature body weight. It is thereby widely accepted that selection on muscle mass induces changes in both the number of prenatally formed myofibers and postnatal hypertrophy (Rehfeldt et al., 2004). Indeed, at day 18 of in ovo development, broiler embryos revealed a 2 -fold higher number 
of myofibers in the cross section of breast muscles than layer chicks (Al-Musawi et al., 2011). Post hatch, at days 7 and 21 of age, both myofiber number and diameter increased for two commercial broiler lines compared with a slow-growing Leghorn-type layer (Scheuermann et al., 2004). By implication, comparing muscles at a given mass, slow-growing chickens must compensate for the reduced number of prenatally formed myofibers by increased hypertrophy. This was demonstrated by Rémignon et al. (1994) on a data set of 55-week-old slow-growing chickens, which showed an increased muscle fiber size when compared to 11-week-old fast-growing birds.

The effects of extensive modification in the development and histology of the skeletal muscle tissue of modern broiler chickens on product quality are controversially debated at present. In spite of the fact that genetic variation in growth traits of chickens is not exhausted yet, and thus allows for further selection (Neeteson-van Nieuwenhoven et al., 2013), it has been stressed that increasing the growth velocity and muscle mass in meat producing species may have reached their physiological limits, possibly resulting in trade-offs regarding product quality (Webb and Casey, 2010). In the case of fast-growing broilers, adverse responses towards selection on muscle mass development could be reflected in a compromised coping ability of supportive vascular and connective tissues, in altered enzymatic activities of skeletal muscle tissue, and in changes in the cation homeostasis (Dransfield and Sosnicki, 1999; Sandercock et al., 2006, 2009).

From a processors' and customers' standpoint, alterations in technological and sensorial properties of chicken meat in particular are of importance. Meat quality defects, which have been linked to selection on growth rate and breast muscle development in chickens, are, for instance, the pale, soft, exudative (PSE)-like and dark, firm, dry (DFD)-like meat conditions, white striping of breast meat, and "wooden" breast condition (Petracci et al., 2009; Kuttappan et al., 2012; Petracci et al., 2013; Kralik et al., 2014; Mudalal et al., 2015). These quality aberrations are associated with altered functional properties of meat, which, depending on the respective defect, can affect $\mathrm{pH}$, color, water-holding capacity, and tenderness of raw and/or cooked meat (Woelfel et al., 2002; Wilhelm et al., 2010; Petracci et al., 2013; Mudalal et al., 2015). However, it was also suggested that, although intense selection on growth performance and breast yield elicited differences in muscle tissue histology and metabolism, there is little evidence of adverse effects on meat quality in chickens besides slight modifications in color (Rémignon and Le Bihan Duval, 2003; Duclos et al., 2007).

In this study, chicken lines strongly divergent in growth rate were compared under standardized conditions in order to investigate the effects of genotypic determined growth rate on functional meat quality and color characteristics of breast fillets. The subject was approached from the following perspectives: (1) comparing fast-growing and slow-growing chicken lines at equal age and at similar body weight (thus, different slaughter ages were applied); and (2) comparing individual chickens with different growth trajectories within fast-growing and slow-growing lines.

\section{Materials and methods}

The experimental protocol was approved by the Animal Policy and Welfare Commissioner of the University of Hohenheim (Stuttgart, Germany).

\subsection{Animals, rearing, and slaughter}

In total, 264 male birds of three lines, a fast-growing commercial broiler and two slow-growing chicken lines, were compared at equal age of 7 and 10 weeks; additionally a sample of broilers was slaughtered at 4 weeks of age to enable comparison between lines at similar weight. The experiment was conducted in the periods from May until July 2012 and from June until August 2013. The slow-growing lines were represented by two experimental meat-type chicken lines kept by the University of Hohenheim and moderately selected for growth rate since 2001. One experimental line was established by crossing the Rhode Island breed with the Silky Fowl; this line carried the sex-linked recessive inhibitor of dermal melanin and dominant fibromelanosis genes, which, in combination, cause hyperpigmentation of skin and skeletal muscle tissue. Thus, this line was characterized by a slow growth rate and its dark skin and meat color (slow-growing, dark-skinned: SGD). The second experimental line was established by crossing the Rhode Island breed with the New Hampshire breed. This line was also slow-growing but exhibited a light (i.e., normal) skin and meat color (slow-growing, light-skinned: SGL). Commercial broilers (Ross 308, Aviagen Group, Huntsville, AL, USA) characterized by a fast growth rate and a light skin color (fastgrowing, light-skinned: FGL) were obtained from a commercial hatchery (Brüterei Süd of the Weser-Ems GmbH \& Co. KG, Regenstauf, Germany).

Birds from each line were randomly distributed to each of two indoor pens (i.e., 6 pens of $5 \mathrm{~m}^{2}$ each) of a ventilated stable with a concrete floor. After 3 weeks, the birds were moved to pens with a floor area of $9 \mathrm{~m}^{2}$ each. All birds were individually identified with numbered tags and kept on wood shavings at a density of $\sim 5 \mathrm{~kg} \mathrm{~m}^{-2}$ with ad libitum access to feed and water. Vaccinations against Marek's disease, coccidiosis, Newcastle disease, infectious bursal disease, and infectious bronchitis were carried out. The room temperature was kept at $34^{\circ} \mathrm{C}$ for the first $72 \mathrm{~h}$ posthatch and gradually reduced thereafter. Lighting was provided for $24 \mathrm{~h}$ for the first $48 \mathrm{~h}$ post hatch and subsequently for $18 \mathrm{~h}$ per day until the end of the experiment. With respect to feeding, there was an attempt to provide standardized, non-limiting conditions on the basis of information gained in multiple previous experiments incorporating Ross 308 broilers. A starter diet was fed from 0 to 3 weeks of age and a grower diet from 3 to 
10 weeks of age (Table 1). Body weight was recorded weekly for each bird.

At slaughter, birds were selected randomly from each pen. Each year at 7 and 10 weeks of age each 20 birds of both slow-growing experimental lines and each 15 commercial broilers were slaughtered, with the exception of 2013, when 14 broilers were slaughtered at an age of 10 weeks. Additionally, 20 and 25 commercial broilers were slaughtered at 4 weeks of age in 2012 and 2013, respectively. Feed was withdrawn approximately $12 \mathrm{~h}$ before slaughter. After electrical stunning $(110 \mathrm{~mA})$, the neck was cut and the birds bled. Carcasses were scalded in a $65^{\circ} \mathrm{C}$ water bath for $20 \mathrm{~s}$ and defeathered in a rotary drum picker. Head and neck as well as feet and shanks were removed. Carcasses were eviscerated manually. After chilling for $2 \mathrm{~h}( \pm 1 \mathrm{~h})$ at $4{ }^{\circ} \mathrm{C}$, the breast muscle (Pectoralis major and minor) was removed and weighed without skin. The left Pectoralis major muscle was stored refrigerated at $4{ }^{\circ} \mathrm{C}$ and used for the determination of meat quality parameters. From the right Pectoralis major muscle, $15 \mathrm{~g}$ slices were harvested at a medial position and stored in plastic tubes at $-20^{\circ} \mathrm{C}$ for pigment analysis.

\subsection{Meat quality analysis}

At $24 \mathrm{~h}$ post-mortem $\mathrm{pH}$ of the left breast muscle was recorded with a $\mathrm{pH}$ meter equipped with a glass electrode, which was calibrated prior to use at $\mathrm{pH} 4.0$ and 7.0. Duplicate measurements at $1 \mathrm{~cm}$ depth on the medial portion of each breast fillet were averaged.

The CIE $L^{*} a^{*} b^{*}$ color profile ( $L^{*}$ - lightness, $a^{*}$ - redness, $b^{*}$ - yellowness) was determined on the cranial portion of the dorsal (adjacent to the bone) surface of the left breast fillet at $24 \mathrm{~h}$ post-mortem. From the $a^{*}$ and $b^{*}$ values the color saturation (chroma, $\left.C^{*}=\left(a^{* 2}+b^{* 2}\right)^{0.5}\right)$ and the hue angle $\left(h^{\circ}=\tan ^{-1}\left(b^{*} / a^{*}\right) \cdot 180 / \pi\right)$ were derived. A chromameter (CR-400, Konica Minolta Sensing Inc., Tokyo, Japan) with an illuminant $C$ and $2^{\circ}$ observer and $8 \mathrm{~mm}$ aperture size setting was used and calibrated prior to each use with a white ceramic tile. For each muscle, four readings were averaged.

The expressible moisture of breast meat was determined at $24 \mathrm{~h}$ post-mortem through the filter paper press method according to van Oeckel et al. (1999). Approximately $0.3 \mathrm{~g}$ of meat was removed from the left breast fillet, placed on filter paper, and pressed between two parallel blocks for $5 \mathrm{~min}$. The areas of pressed meat and expressed moisture were measured using a planimeter, and the ratio of meat to the wet area on the paper $\left(M / W\right.$, in $\left.\mathrm{cm}^{2} \mathrm{~cm}^{-2}\right)$ was multiplied by 100 . Values close to 100 and 0 indicate a high and low waterholding capacity, respectively.

For the determination of cooking loss at $24 \mathrm{~h}$ post-mortem, a sample was cut perpendicular to the fiber orientation from the left breast. The thickness of the samples was standardized to approximately $2 \mathrm{~cm}$. The samples were then placed in a plastic bag and immersed in boiling water with the sealed bag opening extending above the water surface (Petracci and
Table 1. Composition and main characteristics of diets.

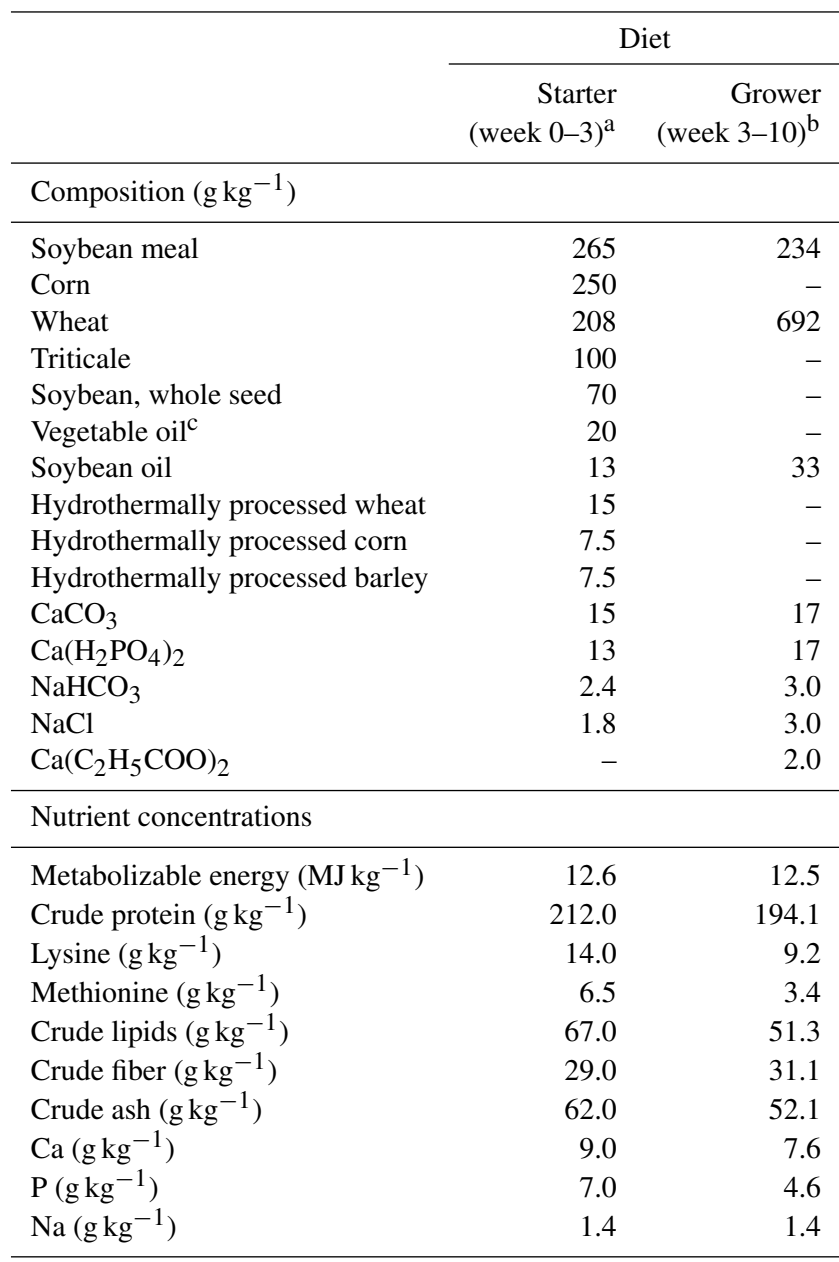

a Premix added to the starter provided the following per kilogram of diet: vitamin A, $15500 \mathrm{IU}$; vitamin D3, $5000 \mathrm{IU}$; vitamin E (DL- $\alpha$-tocopheryl acetate), $70 \mathrm{mg}$; Mn, $80 \mathrm{mg}$; Fe, $60 \mathrm{mg}$; Zn, $50 \mathrm{mg}$; Cu, $17 \mathrm{mg}$; I, $1.01 \mathrm{mg} ; \mathrm{Se}, 0.44 \mathrm{mg}$; Co, $0.38 \mathrm{mg}$; 3-phytase, $600 \mathrm{FTU}$; endo-1,4- $\beta$-xylanase, $12 \mathrm{IU}$; Nasarin (coccidiostat), $48 \mathrm{mg}$; Nicarbazin, $48 \mathrm{mg}$ (coccidiostat).

$\mathrm{b}$ Premix added to the grower provided the following per kilogram of diet: vitamin A, $12000 \mathrm{IU}$; vitamin D3, $3000 \mathrm{IU}$; vitamin E, $40 \mathrm{mg}$; vitamin $\mathrm{K}, 3 \mathrm{mg}$; thiamine, $3 \mathrm{mg}$; riboflavin, $6 \mathrm{mg}$; cobalamin, $30 \mu \mathrm{g}$; niacin, $50 \mathrm{mg}$; pantothenic acid, $12 \mathrm{mg}$; folic acid $1000 \mu \mathrm{g}$; biotin, $100 \mu \mathrm{g} ; \mathrm{Mn}, 108 \mathrm{mg}$; Fe, $80 \mathrm{mg} ; \mathrm{Zn}, 72 \mathrm{mg}$; Cu, $14 \mathrm{mg}$; I, $1.44 \mathrm{mg}$; Se $0.45 \mathrm{mg}$.

${ }^{c}$ Soy oil, palm oil, sunflower oil, rapeseed oil, coconut oil.

Baéza, 2011). The samples were cooked to an internal temperature of $85^{\circ} \mathrm{C}$, whereas the temperature was controlled using a digital insertion thermometer. After cooling the samples to room temperature, moisture was blotted, samples were weighed, and the cooking loss expressed as weight loss during cooking relative to the initial weight of the sample.

\subsection{Pigment determination}

The extraction of hemin (He, in ppm) was carried out in duplicate, according to the Hornsey (1956) method with slight modifications. Slices $(5 \pm 0.02 \mathrm{~g})$ of the right breast muscle were minced and mixed with $20 \mathrm{~mL}$ of $80 \%$ acetone solu- 
tion and $0.5 \mathrm{~mL}$ of $\mathrm{HCl}$. Water was added until total water in the mixture equalled $4.5 \mathrm{~g}$. The mixture was homogenized, held for at least $1 \mathrm{~h}$ at subdued light, and then centrifuged twice. The absorbance of the centrifugate was read at 640 and $730 \mathrm{~nm}$. The hemin content of the extract was calculated as follows:

$\mathrm{He}(\mathrm{ppm})=(A 640-A 730) / 4.8 \times 652 \times$ dilution factor,

where $A 640$ is the absorbance at a wavelength of $640 \mathrm{~nm}$; $A 730$ the absorbance at a wavelength of $730 \mathrm{~nm} ; 4.8$ the millimolar extinction coefficient $\varepsilon_{\lambda} \mathrm{mM}^{-1} \mathrm{~cm}^{-1}$ at $640 \mathrm{~nm}$ (Hornsey, 1956); 652 is the molecular mass of hemin in daltons (Hornsey, 1956).

\subsection{Statistical analysis}

The chicken line (FGL, SGL, and SGD) and the age at slaughter $(4,7$, and 10 weeks) were combined in one treatment effect (line-age). To assure sufficient numbers of observation in spite of limited testing facilities, the experiment was reproduced as a whole in two consecutive years (2012, 2013), using the same experimental protocol, personnel, facilities, and equipment. The individual bird represented one experimental unit. For the evaluation of the effect of treatment on body weight, carcass characteristics, and breast meat quality, the data were analyzed in a full factorial $(7 \times 2)$ experimental design. A general linear model with fixed factors for line-age effect (seven levels), year (two levels), and their interaction was fitted for each response. If the assumptions on the normality of residuals and the homogeneity of the distribution of the residuals were not met, a log-transformation was applied and the assumptions were checked again. For the hemin concentration, a linear mixed model including a random effect accounting for the day of laboratory analysis was applied. For the color traits, only the light-skinned lines were considered. For the evaluation of ultimate $\mathrm{pH}$ values, nine observations exceeding a $\mathrm{pH}$ value of 6.0 had to be removed because otherwise the assumption of normally distributed residuals was violated. For the evaluation of hue angle 14 observations had to be removed because they exhibited $b^{*}$ values lower than zero. Least squares means for treatments were compared pairwise using the adjustment of $P$ values according to the Tukey method for unbalanced data. Differences between treatments with $P<0.05$ were considered significant.

For the analysis of the association of the growth trajectory with meat quality traits, the data set was limited to birds slaughtered at 7 and 10 weeks of age. The GompertzLaird function (Eq. 1) was fitted to the weekly body weight records of each individual bird by non-linear regression, and the asymptotic body weight (Eq. 2) and point of inflexion (Eq. 3), as well as the weight gain at inflexion (Eq. 4), were calculated (Koncagul and Cadirci, 2009):

$$
\begin{aligned}
& \mathrm{BW}_{\text {week }}=\mathrm{BW}_{0} \times e^{\left((L / K)\left(1-e^{-K \text { week }}\right)\right)}, \\
& \mathrm{BW}_{\mathrm{A}}=\mathrm{BW}_{0} \times e^{(L / K)}, \\
& \mathrm{POI}=1 / K \times \ln (L / K), \\
& \mathrm{DG}_{\max }=K \times \mathrm{BW}_{\mathrm{POI}} \ln \left(\mathrm{BW}_{\mathrm{A}} / \mathrm{BW}_{\mathrm{POI}}\right),
\end{aligned}
$$

where $\mathrm{BW}_{\text {week }}$ is the body weight of birds in the respective week, $\mathrm{BW}_{0}$ is the initial weight, $L$ is the initial specific growth rate, $K$ is the exponential decay of the initial specific growth rate, $\mathrm{BW}_{\mathrm{A}}$ is the asymptotic body weight, $\mathrm{POI}$ is the point of inflexion, $\mathrm{DG}_{\max }$ is maximum daily gain (i.e., the weight gain at inflexion), and $\mathrm{BW}$ POI is the body weight at inflexion $\left(\mathrm{BW}_{\mathrm{A}}\right.$ multiplied by 0.368$)$.

The essential growth curve parameters $\left(\mathrm{BW}_{\mathrm{A}}, \mathrm{POI}\right.$, $\mathrm{DG}_{\max }$ ) were compared amongst treatments by adapting the general linear models described before.

The relationships between the growth curve parameters and meat quality and color traits were evaluated for each line separately, controlling for the effects of age ( 7 and 10 weeks) and year by performing partial correlation of the responses for each pair of growth curve parameters and meat quality traits.

The statistical analysis was conducted by $\mathrm{R}$ software version 3.0.2 (R Core Team, R Foundation for Statistical Computing, Vienna, Austria).

\section{Results}

As expected, line and slaughter age significantly contributed to variation in growth performance and carcass quality traits (Table 2), but most parameters were also affected by year and the interaction between line-age effect and year. The superior growth rate of FGL birds was evidenced in both years by significantly $(P<0.05)$ higher body weights at equal slaughter age. At 4 weeks of age the body weight of broilers (1423 and $1245 \mathrm{~g}$ in 2012 and 2013, respectively) was similar or lower compared to 10-week-old slow-growing birds (1468 to $1984 \mathrm{~g}$ ). At equal slaughter age, commercial broilers exhibited substantially increased dressing percentages compared to both slow-growing lines $(P<0.05)$. In the first year, the breast weights from commercial broilers were significantly increased compared to those of slow-growing birds $(P<0.05)$, irrespective of the age and body weight at slaughter. However, in the second year, the weight of the breast from 4-week-old FGL broilers (204 g) was similar to the breast weights of both slow-growing lines slaughtered at an age of 10 weeks (215 and $178 \mathrm{~g}$ for SGL and SGD birds, respectively; $P>0.05)$. The breast yields of the slow-growing lines were still significantly $(P<0.05)$ lower than those of 4-week-old broilers for both years of the experiment.

The 7-week-old and 10-week-old FGL broilers exhibited significantly higher ultimate $\mathrm{pH}$ values $(\mathrm{pH}$ measured at $24 \mathrm{~h}$ post-mortem) than 4-week-old broilers ( $\mathrm{pH}$ values from 5.63 
Table 2. Effect of the combination of chicken line, slaughter age, and year on body weight and carcass composition.

\begin{tabular}{|c|c|c|c|c|c|c|c|c|c|}
\hline \multirow{2}{*}{\multicolumn{2}{|c|}{ Line-age ${ }^{\mathrm{a}}$}} & \multicolumn{2}{|c|}{ Weight at slaughter ${ }^{\mathrm{b}}, \mathrm{g}$} & \multicolumn{2}{|c|}{ Dressing percentage ${ }^{\mathrm{c}}, \%$} & \multicolumn{2}{|c|}{ Breast weight $^{\mathrm{b}}, \mathrm{g}$} & \multicolumn{2}{|c|}{ Breast yield ${ }^{\mathrm{b}}, \%$} \\
\hline & & 2012 & 2013 & 2012 & 2013 & 2012 & 2013 & 2012 & 2013 \\
\hline \multirow[t]{2}{*}{ SGL } & 7 weeks & $1202 \mathrm{e}$ & $1164 \mathrm{e}$ & $63.1 \pm 0.31 d$ & $64.3 \pm 0.31 d$ & $124 \mathrm{f}$ & $111 \mathrm{e}$ & $10.3 \mathrm{~cd}$ & $9.8 \mathrm{e}$ \\
\hline & 10 weeks & $1761 \mathrm{cx}$ & $1984 \mathrm{cy}$ & $65.6 \pm 0.31 c$ & $66.8 \pm 0.31 c$ & $198 d$ & $215 c$ & $11.2 \mathrm{c}$ & $10.8 \mathrm{~d}$ \\
\hline \multirow[t]{2}{*}{ SGD } & 7 weeks & 1167 ex & $1006 f y$ & $63.1 \pm 0.31 \mathrm{~d}$ & $63.4 \pm 0.31 d$ & $116 f x$ & $92 f y$ & $9.9 \mathrm{~d}$ & $9.2 \mathrm{e}$ \\
\hline & 10 weeks & $1468 \mathrm{dy}$ & $1624 d x$ & $63.6 \pm 0.31 \mathrm{dy}$ & $66.6 \pm 0.31 \mathrm{cx}$ & 146 ey & $178 \mathrm{dx}$ & $9.9 \mathrm{dy}$ & $11.0 \mathrm{dx}$ \\
\hline \multirow[t]{3}{*}{ FGL } & 4 weeks & $1423 \mathrm{dx}$ & 1245 ey & $65.5 \pm 0.31 \mathrm{cy}$ & $67.2 \pm 0.28 \mathrm{cx}$ & $261 c x$ & $204 c d y$ & $18.4 \mathrm{bx}$ & $16.4 \mathrm{cy}$ \\
\hline & 7 weeks & $3082 b$ & $2880 \mathrm{~b}$ & $72.2 \pm 0.36 b$ & $72.1 \pm 0.36 b$ & $604 b$ & $526 b$ & $19.6 \mathrm{ab}$ & $18.0 \mathrm{~b}$ \\
\hline & 10 weeks & $4668 \mathrm{a}$ & $4450 \mathrm{a}$ & $74.7 \pm 0.36 \mathrm{a}$ & $75.3 \pm 0.37 \mathrm{a}$ & $991 \mathrm{a}$ & $892 \mathrm{ab}$ & $21.2 \mathrm{a}$ & $20.1 \mathrm{a}$ \\
\hline \multicolumn{10}{|c|}{ Level of significance } \\
\hline \multirow{3}{*}{\multicolumn{2}{|c|}{$\begin{array}{l}\text { Line-age }^{\mathrm{a}} \\
\text { Year } \\
\text { Line-age }^{\mathrm{a}} x \text { year }\end{array}$}} & \multirow{3}{*}{\multicolumn{2}{|c|}{$\begin{array}{c}<0.001 \\
0.012 \\
<0.001\end{array}$}} & \multicolumn{2}{|c|}{$<0.001$} & \multicolumn{2}{|c|}{$<0.001$} & \multicolumn{2}{|c|}{$<0.001$} \\
\hline & & & & \multicolumn{2}{|c|}{$<0.001$} & \multicolumn{2}{|c|}{$<0.001$} & \multicolumn{2}{|c|}{$<0.001$} \\
\hline & & & & \multicolumn{2}{|c|}{$<0.001$} & \multicolumn{2}{|c|}{$<0.001$} & \multicolumn{2}{|c|}{$<0.001$} \\
\hline
\end{tabular}

a-e: within a column, different letters indicate significant differences between treatments $(P<0.05)$.

$\mathrm{x}, \mathrm{y}$ : within a row, different letters indicate significant differences between years $(P<0.05)$.

a Combination of chicken line (SGL, slow-growing light-skinned with $n=80$; SGD, slow-growing dark-skinned with $n=80$; FGL, fast-growing light-skinned with $n=104)$, and slaughter age.

${ }^{b}$ Back-transformed values are presented; pairwise comparisons were based on the log-transformed response.

${ }^{c}$ Data presented as least squares means \pm standard error.

Table 3. Effect of the combination of chicken line, slaughter age, and year on the ultimate $\mathrm{pH}$, water-holding capacity, and pigment concentration of breast meat.

\begin{tabular}{|c|c|c|c|c|c|c|c|c|c|}
\hline & & \multicolumn{2}{|c|}{ Ultimate $\mathrm{pH}$} & \multicolumn{2}{|c|}{ Cooking loss, $\%$} & \multicolumn{2}{|c|}{$M / W^{\mathrm{b}}, \mathrm{cm}^{2} \mathrm{~cm}^{-2}$} & \multicolumn{2}{|c|}{ Hemin, ppm } \\
\hline \multicolumn{2}{|c|}{ Line-age ${ }^{a}$} & 2012 & 2013 & 2012 & 2013 & 2012 & 2013 & 2012 & 2013 \\
\hline \multirow[t]{2}{*}{ SGL } & 7 weeks & $5.67 \pm 0.02 \mathrm{cdy}$ & $5.76 \pm 0.02 \mathrm{abcx}$ & $17.0 \pm 0.7 b c$ & $15.4 \pm 0.7 \mathrm{c}$ & $50.9 \pm 1.6 a b c$ & $54.1 \pm 1.7 \mathrm{a}$ & $8.8 \pm 0.6$ & $11.7 \pm 0.6$ \\
\hline & 10 weeks & $5.66 \pm 0.02 \mathrm{cdy}$ & $5.74 \pm 0.02 \mathrm{abcx}$ & $13.4 \pm 0.7 \mathrm{~d}$ & $16.5 \pm 0.7 \mathrm{c}$ & $49.9 \pm 1.7 \mathrm{abc}$ & $53.2 \pm 1.6 \mathrm{a}$ & $10.0 \pm 0.6$ & $9.6 \pm 0.6$ \\
\hline \multirow[t]{2}{*}{ SGD } & 7 weeks & $5.69 \pm 0.02 \mathrm{bcd}$ & $5.73 \pm 0.02 b c$ & $18.5 \pm 0.7 \mathrm{~b}$ & $15.8 \pm 0.7 \mathrm{c}$ & $57.5 \pm 1.9 \mathrm{a}$ & $53.3 \pm 1.7 \mathrm{a}$ & $9.6 \pm 0.6$ & $13.7 \pm 0.6$ \\
\hline & 10 weeks & $5.71 \pm 0.02 b c$ & $5.73 \pm 0.02 b c$ & $14.8 \pm 0.7 \mathrm{~cd}$ & $16.1 \pm 0.7 \mathrm{c}$ & $54.6 \pm 1.7 \mathrm{ab}$ & $51.5 \pm 1.7 \mathrm{ab}$ & $9.1 \pm 0.6$ & $9.5 \pm 0.6$ \\
\hline \multirow[t]{3}{*}{ FGL } & 4 weeks & $5.63 \pm 0.02 \mathrm{~d}$ & $5.69 \pm 0.01 \mathrm{c}$ & $23.1 \pm 0.7$ ay & $26.6 \pm 0.6 b x$ & $48.8 \pm 1.7 \mathrm{bc}$ & $47.9 \pm 1.5 \mathrm{ab}$ & $11.5 \pm 0.6$ & $10.6 \pm 0.5$ \\
\hline & 7 weeks & $5.79 \pm 0.02 \mathrm{a}$ & $5.79 \pm 0.02 \mathrm{ab}$ & $23.2 \pm 0.8$ ay & $28.4 \pm 0.8 \mathrm{abx}$ & $45.2 \pm 1.9 \mathrm{c}$ & $44.2 \pm 1.9 \mathrm{~b}$ & $8.2 \pm 0.6$ & $10.1 \pm 0.6$ \\
\hline & 10 weeks & $5.77 \pm 0.02 \mathrm{ab}$ & $5.83 \pm 0.02 \mathrm{a}$ & $22.5 \pm 0.8$ ay & $31.3 \pm 0.8 \mathrm{ax}$ & $47.5 \pm 2.0 \mathrm{bc}$ & $51.7 \pm 1.9 \mathrm{ab}$ & $8.8 \pm 0.7$ & $10.3 \pm 0.7$ \\
\hline \multicolumn{10}{|c|}{ Level of significance ${ }^{c}$} \\
\hline \multirow{3}{*}{\multicolumn{2}{|c|}{$\begin{array}{l}\text { Line-age }^{\mathrm{a}} \\
\text { Year } \\
\text { Line-age }^{\mathrm{a}} x \text { year }\end{array}$}} & \multicolumn{2}{|c|}{$<0.001$} & \multirow{2}{*}{\multicolumn{2}{|c|}{$<0.001$}} & \multicolumn{2}{|c|}{$<0.001$} & \multicolumn{2}{|c|}{0.015} \\
\hline & & \multicolumn{2}{|c|}{$<0.001$} & & $<0.001$ & \multicolumn{2}{|c|}{0.833} & \multicolumn{2}{|c|}{0.055} \\
\hline & & \multicolumn{2}{|c|}{0.129} & \multicolumn{2}{|c|}{$<0.001$} & \multicolumn{2}{|c|}{0.100} & \multicolumn{2}{|c|}{0.107} \\
\hline
\end{tabular}

Data presented as least squares means \pm standard error.

a-d: within a column, different letters indicate significant differences between treatments $(P<0.05)$.

$\mathrm{x}, \mathrm{y}$ : within a row, different letters indicate significant differences between years $(P<0.05)$.

${ }^{\text {a }}$ Combination of chicken line (SGL, slow-growing light-skinned with $n=80$; SGD, slow-growing dark-skinned with $n=80$;

FGL, fast-growing light-skinned with $n=104)$, and slaughter age.

${ }^{\mathrm{b}} M / W$ - ratio of meat area relative to the wet area multiplied by 100 after applying the filter paper press method.

${ }^{\mathrm{c}}$ Level of significance for hemin concentration calculated according to Wald $\chi^{2}$ test.

to 5.69 for 4-week-old FGL birds and from 5.79 to 5.83 for 7 - and 10-week-old FGL birds; $P<0.05$; Table 3 ). Notably, most of the observations that exhibited $\mathrm{pH}$ values above pH 6.0 and had to be excluded from the statistical analysis were older broiler chickens. The slow-growing lines did not differ significantly from each other $(\mathrm{pH}$ values from 5.66 to 5.71 and from 5.73 to 5.76 for birds slaughtered in 2012 and 2013, respectively; $P>0.05$ ) and showed ultimate $\mathrm{pH}$ values in between the broilers slaughtered at an age of 7 and 10 weeks and the younger ones. The cooking loss of breast meat was significantly higher for FGL chickens compared with both slow-growing lines (22.5 to $31.3 \%$ for FGL birds compared to 13.4 to $18.5 \%$ for the slow-growing lines; $P<0.05)$, irrespective of the slaughter age and year. Additionally, significant differences in cooking loss were detected among slow-growing chickens in the first year of the experiment $(P<0.05)$, whereas in the second year no differences among slow-growing birds were observed $(P>0.05)$. Cooking losses were slightly, but significantly, higher for 10week-old FGL broilers compared to 4-week-old FGL birds 
Table 5. Effect of the combination of chicken line, slaughter age, and year on Gompertz-Laird growth curve parameters.

\begin{tabular}{|c|c|c|c|c|c|c|c|}
\hline \multirow{2}{*}{\multicolumn{2}{|c|}{ Line-age $^{\mathrm{a}}$}} & \multicolumn{2}{|c|}{$\begin{array}{l}\text { Body weight } \\
\text { (asymptotic) }^{\mathrm{b}}, \mathrm{g}\end{array}$} & \multicolumn{2}{|c|}{ Point of inflexion ${ }^{\mathrm{c}}, \mathrm{d}$} & \multicolumn{2}{|c|}{$\begin{array}{l}\text { Maximum daily } \\
\text { gain }^{\mathrm{b}}, \mathrm{g}\end{array}$} \\
\hline & & 2012 & 2013 & 2012 & 2013 & 2012 & 2013 \\
\hline \multirow[t]{2}{*}{ SGL } & 7 weeks & $2059 \mathrm{~cd}$ & $1889 d$ & $32.6 \pm 1.1 \mathrm{~b}$ & $32.6 \pm 1.1 \mathrm{~b}$ & $33.6 \mathrm{~b}$ & $30.6 \mathrm{~d}$ \\
\hline & 10 weeks & $2328 \mathrm{cy}$ & 3855bx & $36.5 \pm 1.1 \mathrm{aby}$ & $54.1 \pm 1.1 \mathrm{ax}$ & 32.9 by & $39.0 \mathrm{cx}$ \\
\hline \multirow[t]{2}{*}{ SGD } & 7 weeks & $1969 \mathrm{~cd}$ & $1652 d$ & $32.2 \pm 1.1 \mathrm{~b}$ & $33.0 \pm 1.1 b$ & $32.9 b x$ & 27.0ey \\
\hline & 10 weeks & $1771 \mathrm{dy}$ & $3130 \mathrm{cx}$ & $32.9 \pm 1.1$ by & $53.8 \pm 1.1 \mathrm{ax}$ & $26.9 \mathrm{cy}$ & $31.3 \mathrm{dx}$ \\
\hline \multirow[t]{2}{*}{ FGL } & 7 weeks & $5355 b$ & $4545 b$ & $34.1 \pm 1.3 b$ & $32.6 \pm 1.3 b$ & $84.2 \mathrm{a}$ & $77.4 \mathrm{~b}$ \\
\hline & 10 weeks & 6917ay & $8779 \mathrm{ax}$ & $41.7 \pm 1.3$ ay & $53.3 \pm 1.5 \mathrm{ax}$ & $87.4 \mathrm{a}$ & $90.2 \mathrm{a}$ \\
\hline \multicolumn{8}{|c|}{ Level of significance } \\
\hline \multicolumn{2}{|c|}{ Line-age $^{\mathrm{a}}$} & \multicolumn{2}{|c|}{$<0.001$} & \multicolumn{2}{|c|}{$<0.001$} & \multicolumn{2}{|c|}{$<0.001$} \\
\hline \multicolumn{2}{|c|}{ Year } & \multicolumn{2}{|c|}{$<0.001$} & \multicolumn{2}{|c|}{$<0.001$} & \multicolumn{2}{|c|}{0.942} \\
\hline \multicolumn{2}{|c|}{ Line-age $^{\mathrm{a}} x$ year } & \multicolumn{2}{|c|}{$<0.001$} & \multicolumn{2}{|c|}{$<0.001$} & \multicolumn{2}{|c|}{$<0.001$} \\
\hline
\end{tabular}

a-e: within a column, different letters indicate significant differences between treatments $(P<0.05)$

$\mathrm{x}, \mathrm{y}$ : within a row, different letters indicate significant differences between years $(P<0.05)$.

a Combination of chicken line (SGL, slow-growing light-skinned with $n=80$; SGD, slow-growing dark-skinned with

$n=80$; FGL, fast-growing light-skinned with $n=59$ ), and slaughter age.

${ }^{\mathrm{b}}$ Back-transformed values are presented; pairwise comparisons were based on the log-transformed response.

${ }^{\mathrm{c}}$ Data presented as least squares means \pm standard error.

lines. Within the lines, significant partial correlations between growth curve parameters and functional meat properties were detected (Table 6). For broilers, BW $\mathrm{A}$ was significantly negatively (i.e., favorably) associated with cooking loss $(r=-0.32 ; P<0.05)$ and positively with $M / W$ values $(r=0.28 ; P<0.05)$. Body weight at maturity was also negatively correlated to cooking loss for SGL birds $(r=-0.26$; $P<0.05)$. A delayed POI correlated significantly with reduced cooking losses $(r=-0.24 ; P<0.05)$ and increased $a^{*}$ values $(r=0.25 ; P<0.05)$ of the breast meat from SGL chickens. The $\mathrm{DG}_{\max }$ was significantly positively related to ultimate $\mathrm{pH}(r=0.29 ; P<0.05)$ and negatively to the lightness $(r=-0.29 ; P<0.05)$ of breast meat from broilers. Interestingly, cooking loss was significantly negatively correlated to $\mathrm{DG}_{\mathrm{max}}$ in both slow-growing lines $(r=-0.24$ and -0.36 for SGL and SGD birds, respectively; $P<0.05)$ but not within the fast-growing broilers.

\section{Discussion}

In the present experiment, the effects of growth rate and growth potential on breast meat quality and color of chickens were investigated. The experimental design allowed partly accounting for confounding variables (age and body weight) by applying an additional (lower) slaughter age to broilers. Studies on the effect of selecting for growth performance on meat quality of poultry species, which have been conducted before, were either based on comparison at similar live weight (e.g., N'dri et al., 2007), which corresponds well to practical scenarios but implies that the age of slowgrowing chickens at slaughter is markedly increased, or at an equal chronological age of chicken strains (e.g., Berri et
Table 6. Residual Pearson product-moment correlation coefficients between Gompertz-Laird growth curve parameters and breast meat quality traits by line.

\begin{tabular}{llrrrr}
\hline Line $^{\mathrm{a}}$ & Growth & \multicolumn{4}{c}{ Trait $^{\mathrm{c}}$} \\
\cline { 3 - 6 } & parameter $^{\mathrm{b}}$ & $\mathrm{pHu}$ & $\mathrm{CL}$ & $M / W$ & $\mathrm{He}$ \\
\hline SGL & $\mathrm{BW}_{\mathrm{A}}$ & 0.12 & $-0.26^{*}$ & 0.00 & -0.08 \\
& POI & 0.16 & $-0.24^{*}$ & -0.07 & -0.10 \\
& DG $_{\max }$ & 0.16 & $-0.24^{*}$ & $0.22^{*}$ & 0.03 \\
$\mathrm{SGD}$ & $\mathrm{BW}$ & 0.06 & -0.11 & $0.23^{*}$ & -0.05 \\
& POI & 0.17 & 0.01 & 0.11 & 0.09 \\
& DG & -0.16 & $-0.36^{* *}$ & 0.06 & 0.06 \\
FGL & $\mathrm{BW}$ & 0.21 & $-0.32^{*}$ & $0.28^{*}$ & 0.19 \\
& POI & 0.16 & -0.05 & 0.20 & 0.17 \\
& DG $_{\max }$ & $0.29^{*}$ & -0.06 & 0.03 & 0.14 \\
\hline
\end{tabular}

Pearson product moment correlation coefficients significantly different from zero are represented with ${ }^{*}$ at $P<0.05$ and ${ }^{* *}$ at $P<0.01$.

a SGL, slow-growing light-skinned with $n=80$; SGD, slow-growing dark-skinned with $n=80$; FGL, fast-growing light-skinned with $n=59$.

${ }^{\mathrm{b}} \mathrm{BW}_{\mathrm{A}}$ - asymptotic body weight; $\mathrm{POI}$ - point of inflexion; $\mathrm{DG}_{\max }$ - maximum daily gain.

${ }^{\mathrm{c}} \mathrm{pHu}$ - ultimate $\mathrm{pH} ; \mathrm{CL}$ - cooking loss; $M / W$ - ratio of meat area relative to the wet area after applying the filter paper press method; $\mathrm{He}$ - hemin concentration.

al., 2001; Lonergan et al., 2003; Sandercock et al., 2009) and turkey lines (Fernandez et al., 2001; Werner et al., 2008), accepting a wide range in body weight.

The broilers could exploit their genetic potential for growth performance and carcass quality. In spite of large variability in growth and carcass traits among individuals at low numbers of observations, they clearly outperformed the slow-growing lines and attained significantly increased body weights at an equal slaughter age as well as markedly 
increased breast muscle yields. The superior growth performance of FGL birds compared to both slow-growing lines was also reflected in the Gompertz-Laird growth curve parameters with the exception of the age at inflexion. Compared to traditional chicken lines, e.g., those analyzed by Moula et al. (2013), the slow-growing experimental lines used in this study were only slightly younger at inflexion and had similar asymptotic weights, while the main difference was represented in the increased growth rate of the latter. Compared with this, the broiler's growth profile was characterized by a further increased maximum daily gain and by an additionally elevated magnitude of the growth curve.

\subsection{Effects of line and slaughter age on the ultimate $\mathrm{pH}$ of breast meat}

In the present study, differences in ultimate $\mathrm{pH}$ between fastand slow-growing lines depended on the confounded effects of age and/or body and breast muscle weight. Thereby, broilers at an age of 4 weeks revealed lower ultimate $\mathrm{pH}$ values than broilers slaughtered at 7 and 10 weeks, the slowgrowing lines being intermediate. In agreement with the results of the present study, Baéza et al. (2012) reported that the ultimate $\mathrm{pH}$ of commercial broilers increased with slaughter age. Berri et al. (2001) found an increased ultimate $\mathrm{pH}$ for the breast muscle of a heavier fast-growing line (commercial selected line) compared with their lighter unselected counterparts (commercial control line). Ultimate $\mathrm{pH}$ values for broilers were significantly increased compared to slowgrowing chickens when compared at similar body weight (approximately $2 \mathrm{~kg}$ ) (N'dri et al., 2007), and for broilers compared to Leghorn chickens at both equal age and weight (approximately $1.5 \mathrm{~kg}$ ) (An et al., 2010). No genotype effect on $\mathrm{pH}$ values was found comparing slow- and fast-growing chicken strains at the same chronological age by Lonergan et al. (2003). Finally, ultimate pH was even elevated for slowgrowing lines compared with broiler strains slaughtered at 8 weeks of age (Sandercock et al., 2009), and for a mediumgrowing line compared with a fast-growing strain slaughtered at 81 days of age (Sirri et al., 2011). Berri et al. (2007) detected a positive genetic relationship between myofiber diameter and ultimate $\mathrm{pH}$, which is possibly rather related to the reduced glycolytic potential of larger myofibers than to an altered enzymatic activity (Berri et al., 2001), suggesting that variation in the size of myofibers in the breast muscle may account for the differences in ultimate $\mathrm{pH}$ detected. Contradictory results between studies can possibly be explained by the relation of the age at slaughter to the age when radial growth of myofibers is accelerated (i.e., age at POI). When slaughtered at an age of 4 weeks, the FGL chickens had just attained about $17 \%$ of their mature body weight and had not reached the POI yet, but at an age of 7 and 10 weeks, they had passed this point. In fact, ultimate $\mathrm{pH}$ was also positively correlated with $\mathrm{DG}_{\max }$ in FGL chickens, indicating that increasing the maximum growth rate through radial and longitudinal enlargement of myofibers reduces the extent of acidification of breast meat. In contrast, ultimate $\mathrm{pH}$ was not associated with maximum growth speed in both slowgrowing lines, indicating that ultimate $\mathrm{pH}$ and peak growth rate follow a non-linear relationship.

\subsection{Effects of line and slaughter age on water-holding capacity of breast meat}

The ability of meat to retain water during storage and cooking is an important functional meat quality attribute, with implications for the processing ability and eating experience of chicken meat. Irrespective of the age at slaughter, fast-growing chickens displayed markedly reduced cooking yields. In contrast, the water-holding capacity of raw meat was somewhat reduced for broilers slaughtered at an age of 7 weeks, but it was acceptable for FGL chickens slaughtered at 4 and 10 weeks of age. No differences in drip loss at days three and six of storage between selected and unselected chicken lines (Berri et al., 2001) or in drip and cook loss between a medium- and a fast-growing strain (Sirri et al., 2011) were found. According to Lonergan et al. (2003), cooking losses did not differ when comparing broilers and their crosses with layers and traditional chickens at equal age, but they were significantly increased for the respective purebred slow-growing lines. It is notable that within slowgrowing birds high maximum daily gain rates were favorably correlated to cooking yields, which was not applicable for the broilers. However, the growth potential of the broilers, given as $\mathrm{BW}_{\mathrm{A}}$, had a favorable association with cooking loss and the expressible moisture of breast meat, indicating that even in fast-growing strains, simultaneous improvements in water retention and growth performance are not precluded but can be achieved by increasing the growth potential rather than the growth speed. A rapid $\mathrm{pH}$ fall and high temperatures during the early post-mortem phase can trigger myofiber shrinkage and impair protein functionality, leading to reduced water retention of muscles (Wilhelm et al., 2010). When the reduction in water-holding capacity is associated with pale color and low ultimate $\mathrm{pH}$, the resulting meat could be referred to as PSE-like meat (Woelfel et al., 2002; Wilhelm et al., 2010). However, cooking losses of commercial broilers slaughtered at 7 and 10 weeks of age were increased compared to 4-week-old broilers, despite high ultimate $\mathrm{pH}$ values. A recently characterized aberration of breast meat quality from commercial broilers, the white-striping defect, was, in contrast to the PSE-like condition, associated with both high $\mathrm{pH}$ and elevated cooking losses (Mudalal et al., 2014, 2015). It has been suggested that the physiological reason for the white-striping defect and/or reduced cooking yields is reductions in myofibrillar and sarcoplasmic protein concentrations of breast meat (Mudalal et al., 2014). This could have resulted in less protein-bound and immobilized water and more free water within myofibers (Pearce et al., 2011) causing a reduced ability of the meat from older and/or heav- 
ier broilers to retain water during cooking compared to meat from the slow-growing lines.

\subsection{Effects of line and slaughter age on color and hemin concentration of breast meat}

Color primarily contributes to the appearance of meat products and plays an important role for the purchase decisions of consumers, particularly with respect to cut-up poultry products. Because melanin has a strong impact on meat color in SGD birds, their color values were not analyzed. When compared at equal age, differences in meat color assessed on the dorsal fillet surface of both light-skinned lines were negligible. Yet, the color of the dorsal fillet surface of 4-week-old FGL birds clearly diverged from the SGL chickens and was significantly brighter and yellower, more intense, and exhibited a significantly greater hue angle. Other studies found that slow-growing genotypes revealed darker (Berri et al., 2001; Sirri et al., 2011) but, in contrast to the present results, redder, and yellower breast meat (Berri et al., 2001; Sandercock et al., 2009). According to N'dri et al. (2007), the $b^{*}$ values of breast meat of broilers did not differ from a slowgrowing line when reared under normal ambient temperatures, but they were increased for broilers at high ambient temperatures. Sirri et al. (2011) reported that $b^{*}$ values were not differing between a broiler and a medium-growing line at equal age, but $a^{*}$ values were significantly elevated for broiler breast meat. Schneider et al. (2012) observed redness of breast meat of younger broilers was increased compared to older broilers, whereas for $L^{*}$ values this trend was reversed. Baéza et al. (2012) found no consistent age-related trend for the redness of breast meat of a commercial broiler. The scattering and refraction of light through the surface and deeper layers of meat are closely related to the extent of $\mathrm{pH}$ decline and the associated alterations in the spacing of the myofibril lattice (Swatland, 2008). Thus, the relationship of reduced fillet lightness to increased maximum growth rate observed for the broiler chickens could result from simultaneous changes in ultimate $\mathrm{pH}$ values. Chicken breast meat redness is influenced by the myoglobin and hemoglobin concentration in the muscle (Boulianne and King, 1998). Berri et al. (2001) detected lower heme-iron levels in selected chicken lines compared to their unselected counterparts, suggesting that selection on growth could result in declined levels of heminic pigment. In contrast, we did not find differences in hemin concentrations in breast meat of broilers compared to SGL birds. Overall, the differences in color between SGL and FGL chickens slaughtered at an equal age, and in the hemin concentration between all three investigated lines, were small, and they do not suggest a close relationship between growth rate and hemin concentration in chicken breast muscle.

\subsection{Potentially confounding factors and implications}

In the present work, the year and its interaction with the experimental treatments (line-age combinations) had effects on most growth, carcass and meat quality traits. Altered rearing and (pre-)slaughter conditions may influence meat quality in a genotype-specific manner and have to be critically considered in view of the significant year effect and its interactions with line-age effect. These confounding variables could also be relevant with respect to contradictory results among different studies. However, in the case of the growth and carcass characteristics, the large effect sizes noted for the treatment factor allowed the reproduction of the results in two consecutive years despite the presence of significant interactions. The same applied to the cooking loss of breast meat. For the other functional properties of the breast meat no significant interactions between year and line-age effect were noted. In contrast, except for the lightness of breast meat, clear statements in regard to line-age effects on most of the color parameters were prevented due to small effect sizes and the presence of significant interactions.

Several studies pointed towards a higher stress susceptibility of chicken strains exhibiting high growth rates, as indicated by increased creatine kinase levels (Branciari et al., 2009; Sandercock et al., 2009). Thereby, particularly under conditions of acute heat stress, creatine kinase activity increased in a broiler line compared to layer chickens, possibly resulting in compromised sarcolemmal integrity (Sandercock et al., 2006). Because our experiment was carried out in the summer months, interactions between ambient temperature and line have to be taken into account and could have contributed to the increased cooking losses of the broiler, particularly the extremely high temperatures in July 2013. Altogether, the external factors such as high ambient temperature during rearing and holding, stress-reduced handling (Berri et al., 2005), and early deboning (Mehaffey et al., 2006) could have been somewhat favorable for the expression of meat quality of slow-growing chickens, which has to be considered when interpreting the results.

\section{Conclusions}

In conclusion, functional breast meat quality varied in certain aspects when comparing slow-growing chicken lines to a fast-growing broiler, but the differences were age- and/or body-weight-dependent. The results suggest that selection on high growth rates, particularly of the pectoral muscle, applied to commercial broilers (i.e., their purebred greatgrandparental lines), could be primarily associated with increased $\mathrm{pH}$ when the body weight of the birds reaches about 40 to $60 \%$ of their growth potential and, possibly, also with impaired water retention of meat during cooking. This situation resembles the recently described white-striping defect of poultry meat. However, within each of the investigated chicken lines, no unfavorable correlations of growth 
curve parameters with breast meat quality were detected. This contradicts the statement that an increased growth rate is per se detrimental for meat quality. Interestingly, the correlation of ultimate $\mathrm{pH}$ and cooking loss with peak growth rate was either significant for the fast-growing line or both slow-growing lines, pointing towards a non-linear relationship of these variables. Thus, breast meat functionality in fast-growing broilers could still be safeguarded by breeding birds for high growth potential, albeit this might not necessarily contribute to improved production efficiency and profitability. This study further implicates that factors inherent to the individual bird, such as genotypic growth rate and growth potential, are relevant for the expression of meat functionality, but the interactions of line with slaughter age and the conditions during rearing, slaughtering, and processing have to be carefully considered. This was exemplified by the often highly significant interactions with year effects.

Data availability. The data sets used and/or analyzed during the current study are available upon request from the corresponding author.

Author contributions. PCM and AVZ developed the concept and design for this study. The methods for data collection were chosen by PCM and AVZ. Data collection was executed by PCM. PCM analyzed the data and prepared the manuscript with contributions from AVZ.

Competing interests. The authors declare that they have no conflict of interest.

Acknowledgements. The authors thank Herrmann Baumgärtner and Carina Lorenz for their valuable technical advice, and Michael Grashorn and Uta Dickhöfer for providing access to their laboratories. Andrea Zipp and Isaiah Okere are gratefully acknowledged for their technical assistance, and Heiko Stegmann, Jan Abegg, and Heidi Hartmann for rearing and slaughtering the birds.

Edited by: Steffen Maak

Reviewed by: Nassim Moula and one anonymous referee

\section{References}

Al-Musawi, S. L., Lock, F., Simbi, B. H., Bayol, S. A. M., and Stickland, N. C.: Muscle specific differences in the regulation of myogenic differentiation in chickens genetically selected for divergent growth rates, Differentiation, 82, 127-135, 2011.

An, J. Y., Zheng, J. X., Li, J. Y., Zeng, D., Qu, L. J., Xu, G. Y., and Yang, N.: Effect of myofiber characteristics and thickness of perimysium and endomysium on meat tenderness of chickens, Poultry Sci., 89, 1750-1754, 2010.
Baéza, E., Arnould, C., Jlali, M., Chartrin, P., Gigaud, V., Mercerand, F., Durand, C., Méteau, K., Le Bihan-Duval, E., and Berri, C.: Influence of increasing slaughter age of chickens on meat quality, welfare, and technical and economic results, J. Anim. Sci., 90, 2003-2013, 2012.

Berri, C., Wacrenier, N., Millet, N., and Le Bihan-Duval, E.: Effect of selection for improved body composition on muscle and meat characteristics of broilers from experimental and commercial lines, Poultry Sci., 80, 833-838, 2001.

Berri, C., Debut, M., Santé-Lhoutellier, V., Arnould, C., Boutten, B., Sellier, N., Baéza, E., Jehl, N., Jégo, Y., Duclos, M. J., and Le Bihan-Duval E.: Variations in chicken breast meat quality: Implications of struggle and muscle glycogen content at death, Brit. Poultry Sci., 46, 572-579, 2005.

Berri, C., Le Bihan-Duval, E., Debut, M., Santé-Lhoutellier, V., Baéza, E., Gigaud, V., Jégo, Y., and Duclos M. J.: Consequence of muscle hypertrophy on characteristics of Pectoralis major muscle and breast meat quality of broiler chickens, J. Anim. Sci., 85, 2005-2011, 2007.

Boulianne, M. and King, A. J.: Meat color and biochemical characteristics of unacceptable dark-colored broiler chicken carcasses, J. Food Sci., 63, 759-762, 1998.

Branciari, R., Mugnai, C., Mammoli, R., Miraglia, D., Ranucci, D., Dal Bosco, A., and Castellini, C.: Effect of genotype and rearing system on chicken behavior and muscle fiber characteristics, J. Anim. Sci., 87, 4109-4117, 2009.

Dransfield, E. and Sosnicki, A. A.: Relationship between muscle growth and poultry meat quality, Poultry Sci., 78, 743-746, 1999.

Duclos, M. J., Berri, C., and Le Bihan-Duval, E.: Muscle growth and meat quality, J. Appl. Poultry Res., 16, 107-112, 2007.

Fernandez, X., Sante, V., Baéza, E., Le Bihan-Duval, E., Berri, C., Remignon, H., Babile, R., Le Pottier, G., Millet, N., Berge, P., and Astruc T.: Post mortem muscle metabolism and meat quality in three genetic types of turkey, Brit. Poultry Sci., 42, 462-469, 2001.

Havenstein, G. B., Ferket, P. R., and Qureshi, M. A.: Carcass composition and yield of 1957 versus 2001 broilers when fed representative 1957 and 2001 broiler diets, Poultry Sci., 82, 15091518, 2003.

Hornsey, H. C.: The colour of cooked cured pork. I.-Estimation of the Nitric oxide-Haem Pigments, J. Sci. Food Agr., 7, 534-540, 1956.

Hunton, P.: 100 Years of poultry genetics, World Poultry Sci. J., 62, 417-428, 2006.

Koncagul, S. and Cadirci, S.: Analysis of growth of broilers with restricting and unrestricting initial body weight in Gompertz-Laird model in different environments, Ital. J. Anim. Sci., 9, 20-25, 2009.

Kralik, G., Djurkin, I., Kralik, Z., Skrtic, Z., and Radisic, Z.: Quality indicators of broiler breast meat in relation to colour, Anim. Sci. Pap. Rep., 32, 173-178, 2014.

Kuttappan, V. A., Brewer, V. B., Apple, J. K., Waldroup, P. W., and Owens, C. M.: Influence of growth rate on the occurrence of white striping in broiler breast fillets, Poultry Sci., 91, 26772685, 2012.

Lonergan, S. M., Deeb, N., Fedler, C. A., and Lamont, S. J.: Breast meat quality and composition in unique chicken populations, Poultry Sci., 82, 1990-1994, 2003. 
Mehaffey, J. M., Pradhan, S. P., Meullenet, J. F., Emmert, J. L., McKee, S. R., and Owens, C. M.: Meat quality evaluation of minimally aged broiler breast fillets from five commercial genetic strains, Poultry Sci., 85, 902-908, 2006.

Moula, N., Michaux, C., Philippe, F. X., Antoine-Moussiaux, N., and Leroy, P.: Egg and meat production performances of two varieties of the local Ardennaise poultry breed: silver black and golden black, Anim. Genet. Resour., 53, 57-67, 2013.

Mudalal, S., Babini, E., Cavani, C., and Petracci, M.: Quantity and functionality of protein fractions in chicken breast fillets affected by white striping, Poultry Sci., 93, 2108-2116, 2014.

Mudalal, S., Lorenzi, M., Soglia, F., Cavani, C., and Petracci, M.: Implications of white striping and wooden breast abnormalities on quality traits of raw and marinated chicken meat, Animal, 9, 728-734, 2015.

N'dri, A. L., Mignon-Grasteau, S., Sellier, N., Beaumont, C., and Tixier-Boichard, M.: Interactions between the naked neck gene, sex, and fluctuating ambient temperature on heat tolerance, growth, body composition, meat quality, and sensory analysis of slow growing meat-type broilers, Livest. Sci., 110, 33-45, 2007.

Neeteson-van Nieuwenhoven, A.-M., Knap, P., and Avendaño, S.: The role of sustainable commercial pig and poultry breeding for food security, Animal Frontiers, 3, 52-57, 2013.

Pearce, K. L., Rosenvold, K., Andersen, H. J., and Hopkins, D. L.: Water distribution and mobility in meat during the conversion of muscle to meat and ageing and the impacts on fresh meat quality attributes - A review, Meat Sci., 89, 111-124, 2011.

Petracci, M. and Baéza, E.: Harmonization of methodologies for the assessment of poultry meat quality features, World Poultry Sci. J., 67, 137-153, 2011.

Petracci, M., Bianchi, M., and Cavani, C.: The European perspective on pale, soft, exudative conditions in poultry, Poultry Sci., 88, 1518-1523, 2009.

Petracci, M., Mudalal, S., Bonfiglio, A., and Cavani, C.: Occurrence of white striping under commercial conditions and its impact on breast meat quality in broiler chickens, Poultry Sci., 92, 16701675, 2013.

Rehfeldt, C., Fiedler, C., and Stickland, N. C.: Number and size of muscle fibres in relation to meat production, in: Muscle development of livestock animals: physiology, genetics, and meat, edited by: te Pas, M. F. W., Everts, M. E., and Haagsman, H. P., CAB International Publishing, Wallingford, UK, 1-38, 2004.

Rémignon, H. and Le Bihan-Duval, E.: Meat quality problems associated with selection for increased production, in: Poultry genetics, breeding and biotechnology, edited by: Muir, W. M. and Aggrey, S. E., CAB International Publishing, Wallingford, UK, 53-66, 2003.

Rémignon, H., Lefaucheur, L., Blum, J. C., and Ricard, F. H.: Effects of divergent selection for body weight on three skeletal muscles characteristics in the chicken, Brit. Poultry Sci., 35, 6576, 1994.
Sandercock, D. A., Hunter, R. R., Mitchell, M. A., and Hocking, P. M.: Thermoregulatory capacity and muscle membrane integrity are compromised in broilers compared with layers at the same age or body weight, Brit. Poultry Sci., 47, 322-329, 2006.

Sandercock, D. A., Barker, Z. E., Mitchell, M. A., and Hocking, P. M.: Changes in muscle cell cation regulation and meat quality traits are associated with genetic selection for high body weight and meat yield in broiler chickens, Genet. Sel. Evol., 41, 8, https://doi.org/10.1186/1297-9686-41-8, 2009.

Scheuermann, G. N., Bilgili, S. F., Tuzun, S., and Mulvaney, D. R.: Comparison of chicken genotypes: myofiber number in pectoralis muscle and myostatin ontogeny, Poultry Sci., 83, 14041412, 2004.

Schmidt, C. J., Persia, M. E., Feierstein, E., Kingham, B., and Saylor, W. W.: Comparison of a modern broiler line and a heritage line unselected since the 1950s, Poultry Sci., 88, 2610-2619, 2009.

Schneider, B. L., Renema, R. A., Betti, M., Carney, V. L., and Zuidhof, M. J.: Effect of holding temperature, shackling, sex, and age on broiler breast meat quality, Poultry Sci., 91, 468-477, 2012.

Sirri, F., Castellini, C., Bianchi, M., Petracci, M., Meluzzi, A., and Franchini, A.: Effect of fast-, medium- and slow-growing strains on meat quality of chickens reared under the organic farming method, Animal, 5, 312-319, 2011.

Swatland, H. J.: How pH causes paleness or darkness in chicken breast meat, Meat Sci., 80, 396-400, 2008.

Van Oeckel, M. J., Warnants, N., and Boucqué, C. V.: Comparison of different methods for measuring water holding capacity and juiciness of pork versus on-line screening methods, Meat Sci., 51, 313-320, 1999.

Webb, E. C. and Casey, N. H.: Physiological limits to growth and the related effects on meat quality, Livest. Sci., 130, 33-40, 2010.

Werner, C., Riegel, J., and Wicke, M.: Slaughter performance of four different turkey strains, with special focus on the muscle fiber structure and the meat quality of the breast muscle, Poultry Sci., 87, 1849-1859, 2008.

Wilhelm, A. E., Maganhini, M. B., Hernández-Blazquez, F. J., Ida, E. I., and Shimokomaki, M.: Protease activity and the ultrastructure of broiler chicken PSE (pale, soft, exudative) meat, Food Chem., 119, 1201-1204, 2010.

Woelfel, R. L., Owens, C. M., Hirschler, E. M., Martinez-Dawson, R., and Sams, A. R.: The characterization and incidence of pale, soft, and exudative broiler meat in a commercial processing plant, Poultry Sci., 81, 579-584, 2002. 